\title{
An unusual hydrogen addition of indolo-2,3-quinodimethanes to dimethylindoles in the presence of 1,3-azoles
}

\author{
P T PERUMAL* and R NAGARAJAN \\ Organic Chemistry Division, Central Leather Research Institute, Adyar, Chennai 600020 \\ e-mail: ptperumal@hotmail.com
}

MS received 22 May 2005

\begin{abstract}
Indolo-2,3-quinodimethane generated in situ from bis-(bromomethyl)indole with NaI/DMF at $70^{\circ} \mathrm{C}$ was expected to undergo cycloaddition with 1,3 -azoles to give carboline derivatives, which form the backbone of many indole alkaloids. However, the reaction did not give the anticipated product but proceeded via hydrogen addition to exocyclic methylene groups, furnishing dimethylindoles in good yields.
\end{abstract}

Keywords. Indolo-2,3-quinodimethane; bis-(bromomethyl)indole; 1,3-azoles; hydrogen addition; dimethylindoles.

\section{Introduction}

$\mathrm{N}$-protected 2,3-disubstituted indoles are generally used as precursors for the in situ generation of indolo2,3-quinodimethanes (2a,b) since, from a structural point of view, they are susceptible to selective 1,4eliminations. Thus N-benzenesulphonyl and N-benzoylindolo-2,3-quinodimethanes (2a,b) can be generated easily from the N-substituted-2,3-bis(bromomethyl)indole (1a,b) by iodide-induced 1,4-eliminations. ${ }^{1}$ The required dibromo compounds $\mathbf{1 a}, \mathbf{b}$, have been synthesized from 2,3-dimethylindole by protection with appropriate acid chloride followed by bromination with NBS. ${ }^{1}$

Over the past twenty years, indolo-2,3-quinodimethanes and their stable analogues have been the focus of considerable interest. ${ }^{2}$ Although indolo-2,3quinodimethanes were earlier implicated by Berg$\operatorname{man}^{3}$ and others ${ }^{4,5}$ as intermediates in alkaloid synthesis and by Hofheinz ${ }^{6}$ in alkaloid rearrangement, research by Marinelli ${ }^{7}$ and especially by Magnus ${ }^{8}$ has demonstrated the enormous utility of these intermediates in synthesis. Other research groups have described the generation and trapping of indolo-2,3quinodimethanes. $^{9-12}$

The heterocyclic diene reactivity of indolo-2,3quinodimethane is primarily determined by the 2 -

\footnotetext{
*For correspondence
}

aminobutadiene structural unit, MNDO calculations, ${ }^{13}$ have also shown that the $\left[\pi^{4 \mathrm{~S}}+\pi^{2 \mathrm{~S}}\right]$-cycloaddition reactions with electron-poor dienophiles are HOMO diene-LUMO dienophile-controlled processes and that the peri- and regio selectivities found in numerous experimental syntheses can be predicted satisfactorily from the homo tropology of $\mathbf{1} .^{14}$ Most reactions of indolo-2,3-quinodimethane and their applications in Diels-Alder reactions that are described are based on the well-known concepts of $o$-quinodimethane chemistry. ${ }^{15}$

Results available in the literature clearly demonstrate that, in comparison with other processes, the indolo-2,3-quinodimethane/Diels-Alder methodology represents the shortest and most elegant method for the preparation of selectively functionalized $[b]-$ anelated indoles (including indole alkaloids and carbazoles). Dimerization of indolo-2,3-quinodimethanes is also reported. ${ }^{12}$

A convenient method for the synthesis of carbazoles involving the Diels-Alder reaction of an indolo-2,3-quinodimethane intermediate with suitable dienophile, furnishing carbazole derivatives has been reported. ${ }^{1}$ We were interested in the synthesis of carboline derivatives by reaction of indolo-2,3quinodimethane with compounds bearing the $\mathrm{C}=\mathrm{N}$ moiety, the anticipated carboline derivative with the 1,3-azole moiety may be a potential DNA intercalating agent. However, the anticipated product was not obtained. 


\section{Experimental section}

\subsection{General}

Melting points were measured in open capillaries and are uncorrected. Analytical thin layer chromatography was performed on precoated sheets of silica gel G of $0.25 \mathrm{~mm}$ thickness containing PF 254 indicator (Merck, Germany). Column chromatography was performed on silica gel (60-120 mesh: Sd fine, Boisar). IR spectra were recorded as $\mathrm{KBr}$ pellets on a Nicolot Impact-400 spectrometer, ${ }^{1} \mathrm{H}$ NMR spectra in $\mathrm{CDCl}_{3}$ at $300 \mathrm{MHz}$ on a Bruker spectrometer (chemical shifts in $\delta$, ppm) using TMS as internal standard, ${ }^{13} \mathrm{C}$ NMR spectra in $\mathrm{CDCl}_{3}$ at $75 \mathrm{MHz}$ and mass spectra using a VG $70-70 \mathrm{H}$ mass spectrometer at $70 \mathrm{ev}$. N-substituted 2,3-dimethylindoles are prepared by following known procedures ${ }^{1}$.

\subsection{General procedure}

A mixture of dibromomethylindole $(5$ mmoles $)$ and 1,3 -azoles ( $25 \mathrm{mmoles}$ ) in DMF at $70^{\circ} \mathrm{C}$ is treated with $\mathrm{NaI}$ ( $25 \mathrm{mmoles})$. The reaction mixture becomes dark brown in colour due to iodine and is stirred for $1 \mathrm{~h}$ at that temperature. The reaction mixture is poured onto a mixture of crushed ice and sodium thiosulphate (saturated, $10 \mathrm{ml}$ ), extracted with ethyl acetate $(3 \times 10 \mathrm{ml})$, dried over anhydrous $\mathrm{Na}_{2} \mathrm{SO}_{4}$ and the solvent distilled. The residue is subjected to a short column packed with silica gel and eluted with ethyl acetate-petroleum ether mixture $(1: 9)$ to afford pure dimethyl indoles.

2.2a N-Benzoyl-2,3-dimethylindole: Prepared by the hydrogen addition of indolo-2,3-quinodimethane 2a generated in situ from dibromomethylindole (1a, $0.407 \mathrm{~g}, 1 \mathrm{mmol})$ with caffeine $(0.485 \mathrm{~g}, 2.5 \mathrm{mmol})$ and $\mathrm{NaI}(0.6 \mathrm{~g}, 4 \mathrm{mmol})$. The crude product was chromatographed using petroleum ether: ethyl acetate $(90: 10)$ to afford $\mathbf{4 a}$ as colourless solid in $86 \%$ yield. IR (KBr): 2919, 1679, 1456, 1357, $748 \mathrm{~cm}^{-1}$; ${ }^{1} \mathrm{H} \mathrm{NMR}\left(300 \mathrm{MHz}, \mathrm{CDCl}_{3}\right) \delta 7.73(d, 1 \mathrm{H}, J=$ $1.2 \mathrm{~Hz}), 7.73-6.78(m, 8 \mathrm{H}), 2.39(s 3 \mathrm{H}), 2.16(s$, $3 \mathrm{H}) ;{ }^{13} \mathrm{C}$ NMR $\left(75 \mathrm{MHz}, \mathrm{CDCl}_{3}\right) \delta 169 \cdot 7,139 \cdot 6$, $137 \cdot 4,136 \cdot 9,134 \cdot 0,132 \cdot 7,129 \cdot 4,128 \cdot 9,128 \cdot 8,128 \cdot 3$, $127 \cdot 4,124 \cdot 1,123 \cdot 7,130 \cdot 0,118 \cdot 4,29 \cdot 7,21 \cdot 3$; Mass $m / z 249\left(M^{+}\right)$; Anal. Calcd. For $\mathrm{C}_{17} \mathrm{H}_{15} \mathrm{NO}$; C, 81.90; $\mathrm{H}, 6.06$; N 5.62\%; Found, C, 81.75; H, 5.81; N, $5 \cdot 76 \%$.

2.2b N-Phenylsulphonyl-2,3-dimethylindole: Prepared from indoloquinodimethane $\mathbf{2} \mathbf{b}$ generated in situ from dibromomethylindole (1b, $0.443 \mathrm{~g}, 1 \mathrm{mmol})$ with caffeine. The crude product was chromatographed from petroleum ether: ethyl acetate $(90: 10)$ to afford $\mathbf{4 b}$ as colourless solid in $90 \%$ yield. IR $(\mathrm{KBr}): \quad 2922, \quad 1445, \quad 1369, \quad 765 \mathrm{~cm}^{-1} ;{ }^{1} \mathrm{H}$ NMR

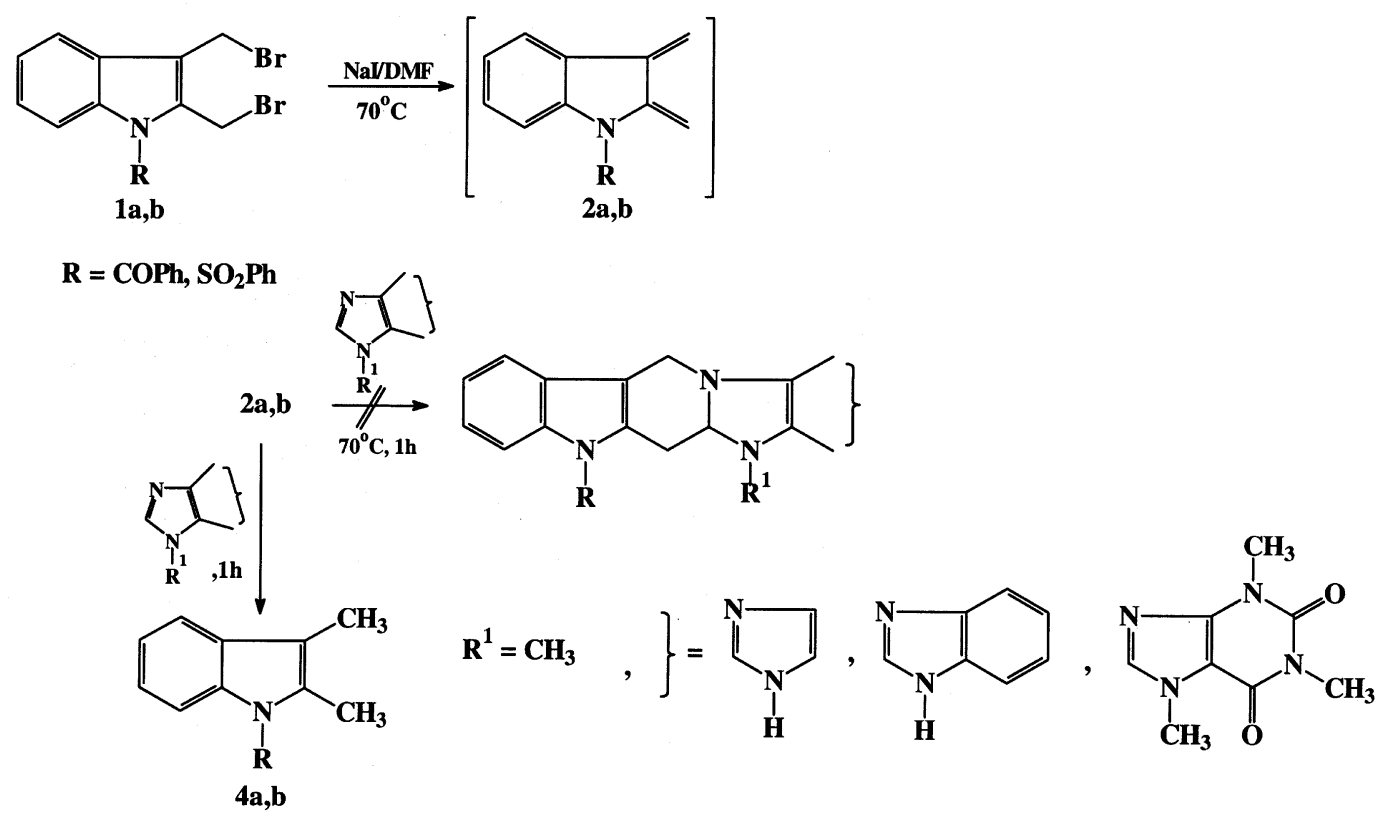

Scheme 1. 


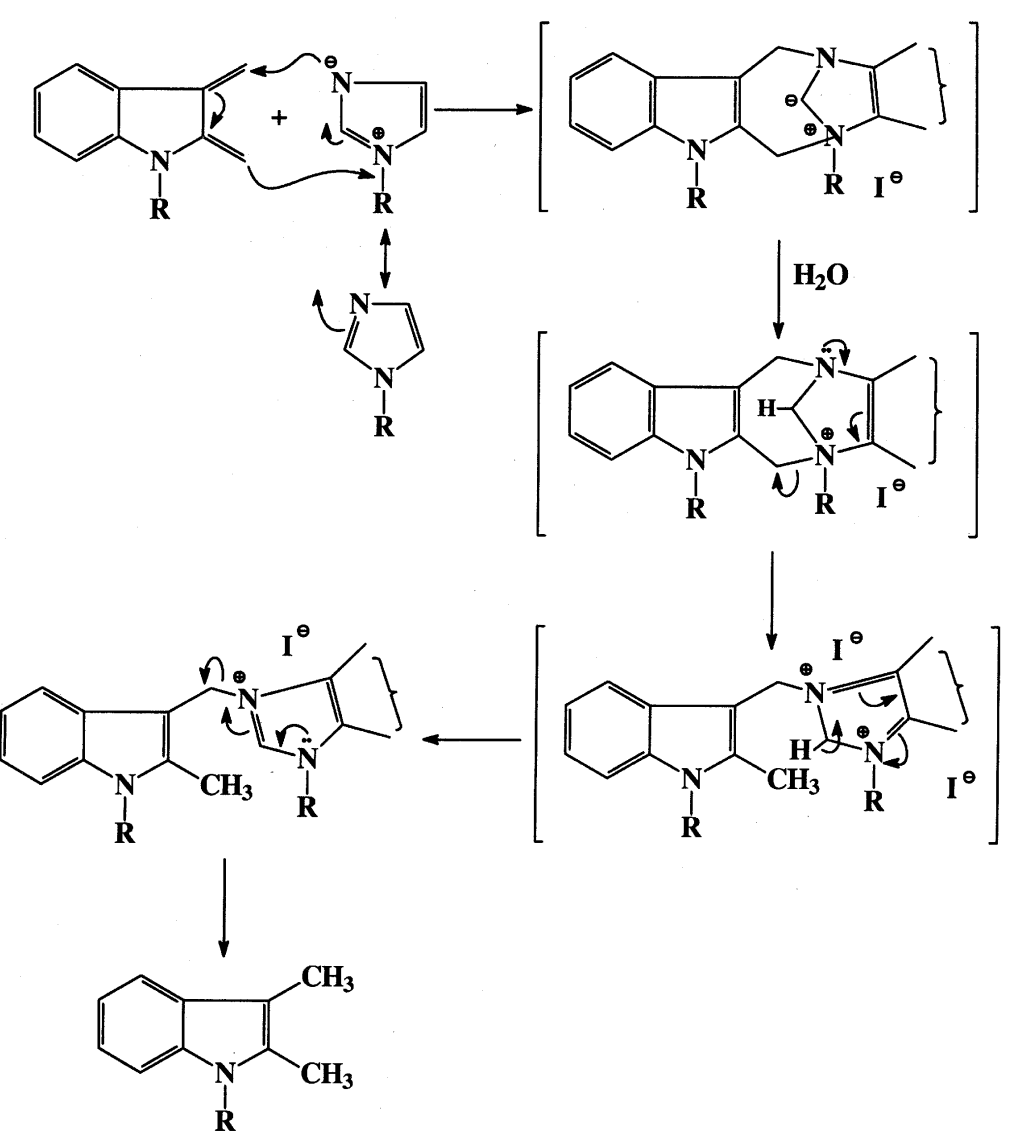

Scheme 2.

Table 1. Synthesis of dimethylindoles.

\begin{tabular}{llc}
\hline Dienes & 1,3-Azoles & Yield of the product (\%) \\
\hline 2a & Benzimidazole & 80 \\
& Caffeine & 90 \\
2b & Benzimidazole & 68 \\
& Caffeine & 86 \\
\hline
\end{tabular}

$\left(300 \mathrm{MHz}, \mathrm{CDCl}_{3}\right) \delta 8.20(d, 1 \mathrm{H}, J=8.2 \mathrm{~Hz}), 7.74$ $(d, 2 \mathrm{H}, J=7.7 \mathrm{~Hz}), 7 \cdot 47-7 \cdot 23(m, 6 \mathrm{H}), 2 \cdot 52(s, 3 \mathrm{H})$, $2 \cdot 11(s, 3 \mathrm{H}) ;{ }^{13} \mathrm{C}$ NMR $\left(75 \mathrm{MHz}, \mathrm{CDCl}_{3}\right) \delta 139 \cdot 2$, $136 \cdot 2,133 \cdot 4,132 \cdot 2,131 \cdot 2,129 \cdot 1,126 \cdot 2,123 \cdot 9$, $123 \cdot 3,118 \cdot 2,116 \cdot 1,114 \cdot 4,12 \cdot 7,8 \cdot 8$; Mass $\mathrm{m} / \mathrm{z} 285$ $\left(M^{+}\right)$; Anal. Calcd. for $\mathrm{C}_{16} \mathrm{H}_{15} \mathrm{NO}_{2} \mathrm{~S} ; \mathrm{C}, 67 \cdot 34 ; \mathrm{H}$, 5.30, N, 4.91\%; found, C, 67.04; H, 5.41; N, 5.24\%.

\section{Results and discussion}

A mixture of N-phenylsulphonyl dibromomethylindole and caffeine in DMF at $70^{\circ} \mathrm{C}$ is treated with $\mathrm{NaI}$. The reaction mixture becomes dark brown in colour and is stirred for $1 \mathrm{~h}$ at that temperature. Then the reaction mixture is poured onto a mixture of crushed ice and sodium thiosulphate, extracted with ethylacetate, dried over anhydrous $\mathrm{Na}_{2} \mathrm{SO}_{4}$ and distilled. The residue is subjected to column chromatography and spectral data clearly show that the product formed is not a carboline. Careful examination of the spectral data reveals that the product obtained is N-phenylsulphonyl 2,3-dimethylindole (scheme 1).

The results are surprising because indolo-2,3-quinodimethane is an unstable compound, that either undergoes cycloaddition with dienophile or dimerises in the absence of the dienophile. The reaction works well with benzimidazole and not with imidazole. Good yields of the dimethylindoles obtained show that some mechanism which greatly suppresses the dimerization, must be operating. The reaction proceeds only in the presence of 1,3-azoles, and no indoles were isolated when the reactions were carried out in the presence of benzoxazole and benzothiazole, which shows that 1,3-nitrogen atoms play some role during the reaction. Similar cycloaddition of 1,3-azoles is also carried out with the $o$-quinodimethane derived from $o$-xylenyl dibromide leads to red-coloured poly- 
meric product. Based on the above results we have proposed a plausible mechanism that accounts for the formation of dimethylindoles (scheme 2).

\section{Conclusion}

In conclusion, we have shown that indolo-2,3-quinodimethane gives unusual products in the presence of 1,3-azoles. The formation of dimethylindoles from indole-2,3-quinodimethane in the presence of 1,3 -azoles is found to be novel, and to the best of our knowledge, is a new result in the field of quinodimethane chemistry.

\section{Acknowledgement}

We thank the Council of Scientific and Industrial Research, New Delhi for financial support.

\section{References}

1. (a) Saroja B and Srinivasan P C 1984 Tetrahedron Lett. 25 5429; (b) Mohanakrishnan A K and Srinivasan P C 1995 J. Org. Chem. 601939

2. Pindur U and Esfanian-Abdoust H 1989 Chem. Rev. 891681

3. (a) Bergman $\mathrm{J}$ and Carlsson R 1977 Tetrahedron Lett. 4663; (b) Bergman J and Carlsson R 1978 Tetrahedron Lett. 4055

4. Driver M, Mathews I T and Sainsbury M 1979 J. Chem. Soc., Perkin 12506

5. Kano S, Sugino E, Shibuya S and Hibino S $1981 \mathrm{~J}$. Org. Chem. 462979
6. Hatheinz W, Sehonholzer P and Berneuer K 1976 Helv. Chim. Acta 591213

7. Marinelli E R 1982 Tetrahedron Lett. 232745

8. (a) Gallagher $\mathrm{T}$ and Magnus $\mathrm{P} 1981$ Tetrahedron 37 3889; (b) Gallagher T, Magnus P and Hoffman J C 1983 J. Am. Chem. Soc. 104 1140; (c) Gallagher T and Magnus P 1983 J. Am. Chem. Soc. 105 2086; (d) Exon C, Gallagher T and Magnus P $1983 \mathrm{~J}$. Am. Chem. Soc. 105 4739; (e) Magnus P, Exon C and Sear N L 1983 Tetrahedron 39 2725; (f) Magnus P and Sear N L 1983 Tetrahedron 40 2795; (g) Magnus P, Gallagher T, Brown P and Pappalardo P 1984 Acc. Chem. Res. 17 35; (h) Magnus P, Gallagher T, Brown $\mathrm{P}$ and Hoffman J C $1984 \mathrm{~J}$. Am. Chem. Soc. 106 2105; (i) Cardwell K, Hewitt B, Ladlow M and Magnus P 1988 J. Am. Chem. Soc. 1102242

9. (a) Kurihara T, Hanakawa M, Wakita T and Harusawa S 1985 Heterocycles 23 2221; (b) Kurihara T, Hanakawa M, Harusawa S and Yoneda R 1986 Chem. Pharm. Bull. Jpn 344545

10. Herslof M and Martin A R 1987 Tetrahedron Lett. 28 3423

11. (a) Haber $\mathrm{M}$ and Pindur U 1991 Tetrahedron 47 1925; (b) Pindur U and Haber M 1991 Heterocycles 321463

12. Vice S F, Nandin de Carvalho H, Taylor N G D and Mitrienko G I 1989 Tetrahedron Lett. 307289

13. (a) Dewar M J S and Thiel W 1977 J. Am. Chem. Soc. 99 4899; (b) Dewar M J S and Thiel W 1977 J. Am. Chem. Soc. 994907

14. (a) Dewar M J S and Thiel W 1977 J. Am. Chem. Soc. 99 4899; (b) Dewar M J S and Thiel W 1977 J. Am. Chem. Soc. 99 4907; (c) Flemming I (ed.) 1976 Frontier orbitals and chemical reactions (New York: Wiley)

15. (a) Oppolzer W 1978 Synthesis 793; (b) Klundt I 1980 Chem. Rev. 80 471; (c) Charlton J L and Alauddin M M 1987 Tetrahedron 43 2873; (d) Funk R L and Vollharat K P C 1980 Chem. Soc. Rev. 941 